\title{
Perioperative factors and pressure ulcer development in postoperative ICU patients: a retrospective review
}

\author{
Objective: To identify variables during surgery that may contribute to \\ the development of pressure ulcers (PUs) in postoperative, intensive \\ care unit (ICU) patients within 72 hours of admission, as well as over \\ their entire ICU admission. Furthermore, to investigate how these \\ variables may impact on the number of PUs acquired. \\ Method: In a three-year retrospective audit, from 1 January 2014 to \\ 31 December 2016, data from the electronic medical records of 3484 \\ postoperative ICU patients in a major Australian metropolitan public \\ hospital were retrieved and analysed to investigate associations \\ between perioperative variables and $\mathrm{PU}$ occurrence. \\ Results: A total of 69 ICU admissions (1.98\%) out of 3484 resulted in \\ at least one PU developing within the ICU. No specific variables were \\ associated with the development of a PU within 72 hours of the \\ patient's ICU admission. Multiple regression Cox analysis showed that
}

\begin{abstract}
length of time in the operating theatre (OT) $(p=0.045)$, surgical specialty $(p<0.001), 1-4$ hypotensive episodes $(p=0.017)$ and $>5$ hypotensive episodes $(p<0.0005)$ were significantly associated with PU risk. Multivariable negative binomial regression demonstrated APACHE II score $(p<0.01)$, OT time $(p<0.01)$ and surgical specialty $(p<0.01)$ were associated with PU number.

Conclusion: There are many risks to skin integrity at the perioperative period, and these risks may exert their effect well into the ICU admission period. It is imperative to identify and mitigate these factors in order to reduce PU incidence, morbidity and mortality. Declaration of interest: There are no known conflicts of interest associated with this manuscript and there has been no financial support for this work that could have influenced its outcome. The authors did not receive any funding for this study.
\end{abstract}

intensive care $\bullet$ perioperative factors $\bullet$ pressure ulcer $\bullet$ retrospective review $\bullet$ skin integrity $\bullet$ surgery

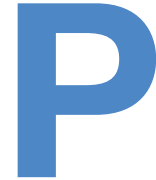

ressure ulcer (PU) refers to localised damage to the skin and underlying soft tissue, usually over a bony prominence or related to the use of a medical device, either in diagnosis or treatment, occurring as a result of prolonged pressure or pressure combined with shear and friction. ${ }^{1}$

The development of nosocomial PU is a significant problem for patients in the critical care setting, leading to considerable morbidity and mortality, lengthening hospital stays and contributing a substantial financial burden to the health-care system. ${ }^{2}$ Compared with the general care population, critically ill patients are at a higher risk of PU due to the interplay of several coexisting factors such as impaired circulation, poor nutrition, immobility and altered consciousness. ${ }^{3,4}$ Similarly, the perioperative environment poses many risks to skin integrity such as anaesthetic agents, vasoactive medications and prolonged immobilisation. 5,6 These threaten skin integrity by creating alterations in blood pressure, tissue perfusion and pressure and pain responses. ${ }^{7}$ Therefore, PU risk may be further confounded in patients admitted to an intensive care unit (ICU) postoperatively. Factors contributing to PU development in postoperative ICU patients are neither fully categorised nor well-studied.

Despite the recent introduction of financial penalties for hospital-acquired conditions in one Australian state, $^{8} \mathrm{PU}$, though largely preventable, remains a difficult problem to address. Various international studies report prevalence rates ranging from 6.6$19.7 \%,{ }^{9-11}$ with incidence rates from $2.68-10 \% .^{9,11,12}$ These rates are higher among ICU patients ${ }^{13}$ and this trend is reflected within the Australian health-care system, with ICUs having the highest reported rates of PU in Australian hospitals. ${ }^{14,15}$ PUs are associated with negative patient outcomes in terms of pain, suffering, loss of function, prolonged hospital stay and increased morbidity and mortality. ${ }^{16,17}$ Between 2001 and 2003, PUs were cited as the primary or secondary cause of more than 920 Australian deaths ${ }^{18}$ and the financial burden attributable to PU is not insignificant, with an estimated treatment cost of AUD\$983 million per annum. ${ }^{19}$ Overall, these statistics highlight the economic wastage associated with a largely avoidable wound, as well as emphasising the need for further research into prevention, intervention and treatment methods for this debilitating condition.

In terms of reducing costs incurred by PU, a targeted preventive approach is likely to be more effective than

*Neha Kumta, ${ }^{1,2}$ Resident Medical Officer; Fiona Coyer, ${ }^{3}$ Professor of Nursing; Michael David, ${ }^{4}$ Biostatistical Consultant

*Corresponding author email: neha.kumta@health.qld.gov.au

1 Sunshine Coast University Hospital, Birtinya, QLD, Australia. 2 University of Queensland, Brisbane, QLD, Australia. 3 School of Nursing, Queensland University of Technology and Intensive Care Services, Royal Brisbane and Women's Hospital, Brisbane, QLD, Australia. 4 Biostatistical Consultant, Faculty of Medicine, University of Queensland, Brisbane, QLD, Australia. 
Table 1. Definitions of variables

\begin{tabular}{|c|c|c|}
\hline Data variable & Definition & Source \\
\hline Sex & Patient's demographic (male/female) & ICU metavision database \\
\hline Age & Patient's demographic (years) & ICU metavision database \\
\hline Type of surgery & $\begin{array}{l}\text { Type of surgery the patient underwent during their index surgical case, broadly categorised by } \\
\text { surgical subspecialty. } \\
\text { Surgical specialty categories: orthopaedics, vascular, cardiothoracic, obstetrics and } \\
\text { gynaecology, neurosurgery, ear nose and throat, plastics and maxillofacial, urology, } \\
\text { gastrointestinal, endocrine, other }\end{array}$ & ICU metavision database \\
\hline $\begin{array}{l}\text { Length of time in } \\
\text { operating theatre }\end{array}$ & $\begin{array}{l}\text { Cumulative length of time spent in the operating theatre during each ICU visit, defined as the } \\
\text { time between the patient entering and exiting the theatre }\end{array}$ & ORMIS database ${ }^{\star}$ \\
\hline $\begin{array}{l}\text { Number of hypotensive } \\
\text { episodes in operating } \\
\text { theatre }\end{array}$ & $\begin{array}{l}\text { Number of the periods of hypotension experienced in the operating room during the index } \\
\text { surgical case. Sub-categorised into } 0 \text { hypotensive epsiodes; } 1-4 \text { hypotensive episodes; and } \\
>4 \text { hypotensive episodes. Hypotension defined as systolic blood pressure }<100 \mathrm{mmHg}\end{array}$ & AARK database $^{\dagger}$ \\
\hline $\begin{array}{l}\text { Administration of } \\
\text { vasopressors in operating } \\
\text { theatre }\end{array}$ & $\begin{array}{l}\text { Use of any vasopressive medication during the patient's time in operating room for the index } \\
\text { surgical case (yes/no). Vasopressors considered: vasopressin, dobutamine, dopamine, } \\
\text { adrenaline, noradrenaline, phenylephrine, metaraminol }\end{array}$ & AARK database $^{\dagger}$ \\
\hline ICU length of stay & Patient's total length of stay in intensive care unit & ICU metavision database \\
\hline APACHE II Score ${ }^{\ddagger}$ & Acute Physiology and Chronic Health Evaluation II; severity of disease classification system & ICU metavision database \\
\hline $\begin{array}{l}\text { Development of pressure } \\
\text { ulcer in ICU }\end{array}$ & If yes, date, time, location and stage of each pressure ulcer & ICU metavision database \\
\hline \multicolumn{3}{|c|}{$\begin{array}{l}\text { ICU-intensive care unit; }{ }^{*} \text { ORMIS-Operating Room Management Information System; }{ }^{\dagger} \text { AARK-Automated Anaesthetic Record Keeping System; }{ }^{\ddagger} \text { APACHE II score-Acute Physiology and } \\
\text { Chronic Health Evaluation II score. }{ }^{33} \text { Severity of disease classification system used to estimate mortality for adult patients upon ICU admission. Scored using routine physiological } \\
\text { measurements: temperature, mean arterial pressure, heart rate, respiratory rate, alveolar-arterial oxygenation gradient, arterial pH or HCO }{ }_{3} \text {, serum sodium concentration, serum potassium } \\
\text { concentration, serum creatinine, haematocrit, white blood cell count, Glasgow Coma Score, age, the presence of chronic health problems (cirrhosis, heart failure, respiratory failure, } \\
\text { immunocompromised state). APACHE II scores range from 0-71 points }\end{array}$} \\
\hline
\end{tabular}

Table 2. Demographic baseline data $(n=3484)$

\begin{tabular}{|c|c|c|c|}
\hline Variable & & $\begin{array}{l}\text { Total sample } \\
\text { n (\%*) }\end{array}$ & $\begin{array}{l}\text { Pressure ulcers } \\
\text { n (\%*) }\end{array}$ \\
\hline Gender & Male & 1987 (57) & $47(2.4)$ \\
\hline \multirow{10}{*}{$\begin{array}{l}\text { Surgical specialty } \\
\text { (missing=234) }\end{array}$} & Cardiothoracic & $37(1.1)$ & $4(10.8)$ \\
\hline & Endocrine & $28(0.9)$ & $0(0)$ \\
\hline & $\begin{array}{l}\text { Ear, nose and throat; } \\
\text { plastics; maxillofacial }\end{array}$ & 413 (12.7) & $3(0.7)$ \\
\hline & Gastroinstestinal & $832(25.6)$ & $22(2.6)$ \\
\hline & Neurosurgery & 773 (23.9) & $12(1.6)$ \\
\hline & $\begin{array}{l}\text { Obstetrics and } \\
\text { gynaecology }\end{array}$ & $110(3.4)$ & $1(0.9)$ \\
\hline & Orthopaedics & $381(11.7)$ & $15(3.9)$ \\
\hline & Urology & $190(5.8)$ & $2(1.1)$ \\
\hline & Vascular & $601(18.5)$ & $9(1.5)$ \\
\hline & Other & $110(3.4)$ & $1(0.9)$ \\
\hline \multirow{2}{*}{$\begin{array}{l}\text { Vasopressor given } \\
\text { intraoperatively } \\
\text { (missing=607) }\end{array}$} & Yes & $2423(84.2)$ & $61(2.5)$ \\
\hline & No & 454 (15.8) & $0(0)$ \\
\hline
\end{tabular}

one focused on treatment. Preventing PU involves determining what constitutes appropriate risk and undertaking precautions to reduce that risk. However, there remains a distinct lack of consensus on which risk factors are of greatest significance, for example, studies differ on the significance of factors such as time spent in the operating theatre (OT), ${ }^{20-22}$ vasopressor use, ${ }^{23-25}$ and age. ${ }^{26,27}$ Additionally, although a number of studies have investigated PU development in ICU patients, ${ }^{28-31}$ research on PU within the perioperative period is more limited, as is research on PU in postoperative ICU patients. Both being critically ill and being in theatre for prolonged periods of time are independent determinants for PU development ${ }^{32}$ and presumably the risk is greater when the two intersect. Therefore, this group of patients may be extremely vulnerable to PU and interventions targeted towards this subpopulation may be particularly effective in reducing PU occurrence.

Information regarding the timeframe for PU onset is scant. After reviewing data from clinical, animal and in vitro studies, Gefen ${ }^{33}$ suggests sub-dermal tissue damage occurs between 1-6 hours after sustained loading (sustained pressure or loading of body weight onto a surface). However, research has established that pressure exerted in deeper tissues is greater than that at the skin surface and, due to increased metabolic requirements, muscle tissue is damaged before skin and subcutaneous tissue. ${ }^{34}$ Therefore, although damage may occur within hours after prolonged pressure, some authors contend it may not be evident at the skin level until 1-3 days later. ${ }^{35,36}$ 
Table 3. Clinical baseline data $(n=3484)$

\begin{tabular}{|c|c|c|c|}
\hline Variable & $\begin{array}{l}\text { Mean of } \\
\text { all visits }\end{array}$ & $\begin{array}{l}\text { Pressure ulcer } \\
\text { mean (SD) }\end{array}$ & $\begin{array}{l}\text { No pressure } \\
\text { ulcer mean (SD) }\end{array}$ \\
\hline Age, years & 59.28 & $59.31(16.67)$ & $57.74(18.28)$ \\
\hline $\begin{array}{l}\text { Number of episodes } \\
\text { of hypotension in OT } \\
\text { (missing }=234 \text { ) }\end{array}$ & 4.10 & $2.74(5.07)$ & $4.13(9.62)$ \\
\hline $\begin{array}{l}\text { OT time, minutes } \\
\text { (missing }=234 \text { ) }\end{array}$ & 266.44 & 496.35 (455.77) & $266.44(189.75)$ \\
\hline ICU length of stay, hours & 41.02 & 308.50 (259.72) & 38.67 (58.79) \\
\hline APACHE II score & 12.38 & $18.96(7.24)$ & $12.24(5.45)$ \\
\hline
\end{tabular}

Table 4. Number of pressure ulcers of each category $(n=96)$

\begin{tabular}{|l|lll|}
\hline $\begin{array}{l}\text { Category } \\
\text { (missing=6) }\end{array}$ & $\begin{array}{l}\text { Total } \\
(\mathbf{n = 9 6 )}\end{array}$ & $\begin{array}{l}\mathbf{< 7 2} \text { hours }(\mathbf{n = 3 5 )} \\
\mathbf{n}\left(\%^{*}\right)\end{array}$ & $\begin{array}{l}\mathbf{> 7 2} \text { hours }(\mathbf{n = 6 1 )} \\
\mathbf{n}(\% *)\end{array}$ \\
\hline Mucosal & 9 & $3(9.68)$ & $6(10.17)$ \\
\hline Category I & 17 & $8(25.81)$ & $9(15.25)$ \\
\hline Category II & 49 & $11(34.48)$ & $38(64.41)$ \\
\hline Category III & 7 & $5(16.13)$ & $2(3.39)$ \\
\hline Category IV & 1 & $1(3.23)$ & $0(0)$ \\
\hline Suspected deep tissue injury & 4 & $2(6.45)$ & $2(3.39)$ \\
\hline Uncategorisable & 3 & $1(3.23)$ & $2(3.39)$ \\
\hline Missing data on category & 6 & 4 & 2 \\
\hline *\% of available data & & &
\end{tabular}

Table 5. Number of pressure ulcers of each location $(n=96)$

\begin{tabular}{|c|c|c|c|}
\hline Location & $\begin{array}{l}\text { Total }(n=96) \\
n(\%)\end{array}$ & $\begin{array}{l}<72 \text { hours }(n=35) \\
n(\%)\end{array}$ & $\begin{array}{l}>72 \text { hours }(n=61) \\
n(\%)\end{array}$ \\
\hline Shoulder/arm & 3 & $2(5.71)$ & $1(1.64)$ \\
\hline Abdomen & 3 & $2(5.71)$ & $1(1.64)$ \\
\hline Sacrum & 13 & 9 (25.71) & $4(6.56)$ \\
\hline Occipital & 5 & $1(2.86)$ & $4(6.56)$ \\
\hline Nose & 28 & 5 (14.29) & 23 (37.71) \\
\hline Neck/jaw & 6 & $1(2.86)$ & $5(8.20)$ \\
\hline Mouth/lip & 11 & $4(11.43)$ & 7 (11.48) \\
\hline Leg & 6 & $5(14.29)$ & $1(1.64)$ \\
\hline Hip/buttocks & 6 & $3(8.57)$ & $3(4.92)$ \\
\hline Heel/foot & 10 & $3(8.57)$ & 7 (11.48) \\
\hline Genitalia & 1 & $0(0)$ & $1(1.64)$ \\
\hline Ear & 1 & $0(0)$ & $1(1.64)$ \\
\hline Breast & 1 & $0(0)$ & $1(1.64)$ \\
\hline Back & 2 & $0(0)$ & $2(3.28)$ \\
\hline
\end{tabular}

\section{Variables}

Variables examined were sex, age, type of surgery, length of time in the operating theatre (OT), number of hypotensive episodes in the OT where systolic blood pressure was $<100 \mathrm{mmHg}$, administration of inotropes (e.g. vasopressors, dobutamine, adrenaline) in the OT, ICU length of stay, Acute Physiology and Chronic Health Evaluation II (APACHE II score) ${ }^{37}$ and the number and category of any PU that developed during the ICU admission. Definitions for each of the study variables are included in Table 1 . Pressure ulcers were categorised according to the National Pressure Ulcer Advisory Panel (NPUAP) Pressure Ulcer Classification System. ${ }^{1}$

\section{Procedure}

Following institutional ethical and research governance approvals, information on patient demographics, comorbidities, PU assessments and ICU length of stay was obtained electronically from routine clinical documentation recorded on the ICU clinical database (MetaVision). These data were combined with additional variables on intraoperative management 
obtained from surgical and anaesthetic databases, Operating Room Management Information System (ORMIS) and Automated Anaesthetic Record Keeping System (AARK), respectively.

\section{Analysis}

Data were entered into the Statistical Package for the Social Sciences (SPSS) (Version 21.0, US). Descriptive statistics were analysed using frequencies and means. PU incidence during the first 72 hours of ICU admission was measured as the number of patient admissions that resulted in a new PU within 72 hours of admission divided by the total number of patient admissions. Total postoperative PU incidence was measured as the number of patient admissions that resulted in a new PU divided by the total number of patient admissions. ${ }^{39}$

We considered each patient admission to the ICU as a discrete case, rather than focusing on each patient as a discrete case. However, some patients had multiple ICU admissions during the course of our study; for this reason a clustering adjustment based on individual patients was made for all statistical models. Furthermore, the variables of surgical speciality, number of hypotensive episodes in the OT and administration of vasopressors in the OT were taken from the index surgical case-the operation immediately preceding each ICU admission. The recorded APACHE II scores were those calculated at the time of this index surgical case. However, some patients required multiple operations during one ICU visit. Therefore, the decision was made to consider cumulative time spent in the OT during one ICU visit as a variable in our analysis as this combined OT time was believed to be more representative of PU risk.

For all analyses, initial univariate analyses were conducted for each perioperative variable to determine any associations between these variables and PU development. To avoid excluding potential predictors too early, variables with $\mathrm{p}<0.10$ at univariate analysis were selected as potential candidates for entry into final multivariate analysis, in which $\mathrm{p}<0.05$ was considered statistically significant.

Risk factors for PU development within 72 hours of ICU admission were assessed using a logistic regression model with a clustering adjustment. Associations between perioperative variables and PU number were analysed using a negative binomial regression model, also with a clustering adjustment. When considering risk factors for PU development over the entire ICU admission, survival analyses was conducted using a Cox proportional hazards model with a clustering adjustment to study the effects of perioperative variables over an extended period of time.

Some patients were missing data on OT time, hypotensive episodes in OT, vasopressor administration and PU stage, therefore a complete case analysis was performed, disregarding those patients without full sets of data.
Table 6. Univariable Cox analysis-predictors for pressure ulcer development over intensive care unit admission

\begin{tabular}{|c|c|c|c|c|}
\hline \multirow[t]{2}{*}{ Predictor } & \multicolumn{4}{|c|}{ Univariable analysis } \\
\hline & $\begin{array}{l}\text { Unadjusted } \\
\text { HR }\end{array}$ & $95 \% \mathrm{Cl}$ & p-value & $\begin{array}{l}\text { Overall } \\
\text { p-value }\end{array}$ \\
\hline Age & 0.99 & $0.97-1.00$ & 0.11 & 0.11 \\
\hline APACHE II score & 0.94 & $0.91-0.98$ & $<0.01$ & $<0.01$ \\
\hline Vasopressor administration & 1.00 & Undefined & 1.00 & 1.00 \\
\hline OT time & 1.03 & $1.01-1.05$ & 0.01 & 0.01 \\
\hline \multicolumn{5}{|l|}{ Surgical speciality } \\
\hline Cardiothoracic (reference level) & 1 & & & $<0.01$ \\
\hline $\begin{array}{l}\text { Ear, nose and throat; plastics; } \\
\text { maxillofacial }\end{array}$ & 1.97 & $0.69-5.68$ & 0.21 & \\
\hline Endocrine & 1 & Undefined & 1.00 & \\
\hline Gastrointestinal & 0.58 & $0.29-1.13$ & 0.11 & \\
\hline Neurological & 0.64 & $0.27-1.50$ & 0.31 & \\
\hline Obstetrics and gynaecology & 2.34 & $1.38-3.99$ & $<0.02$ & \\
\hline Orthopaedics & 1.66 & $0.87-3.16$ & 0.13 & \\
\hline Other & 0.34 & $0.19-0.58$ & $<0.01$ & \\
\hline Urology & 2.62 & $0.72-9.59$ & 0.14 & \\
\hline Vascular & 0.61 & $0.28-1.32$ & 0.21 & \\
\hline \multicolumn{5}{|l|}{ Hypotensive episodes } \\
\hline None (reference level) & 1 & & & 0.06 \\
\hline $1-4$ & 1.35 & $0.79-2.33$ & 0.28 & \\
\hline$>5$ & 2.18 & $1.12-4.24$ & 0.02 & \\
\hline
\end{tabular}

\section{Ethical considerations}

Ethical and research governance approvals were obtained from the relevant hospital and university human research ethics committees before this study began (HREC/16/QRBW/462). Data were retrieved in a de-identified format in order to protect patients' privacy.

\section{Results}

A total of 3484 discrete patient admissions were studied, of which 69 resulted in the development of at least one PU, giving an incidence of $1.98 \%$ over the three years of our study. Some admissions resulted in multiple PUs, giving a total of 96 PUs in our study sample. In 25 patient admissions, at least one PU developed within 72 hours of admission, giving an incidence of $0.72 \%$ for this time period. Again, as some admissions resulted in multiple PUs, there were a total of 35 PUs that occurred within 72 hours of ICU admission. Baseline demographic data are presented in Tables $2-5$. Statistical data are presented in Tables 6-11. 
Table 7. Multivariable Cox analysis-predictors for pressure ulcer development over intensive care unit admission

\begin{tabular}{|c|c|c|c|c|}
\hline \multirow[t]{2}{*}{ Predictor } & \multicolumn{4}{|c|}{ Multivariable analysis } \\
\hline & $\begin{array}{l}\text { Adjusted } \\
\text { HR }\end{array}$ & $95 \% \mathrm{Cl}$ & p-value & $\begin{array}{l}\text { Overall } \\
\text { p-value }\end{array}$ \\
\hline APACHE II score & 0.96 & $0.91-1.01$ & 0.09 & 0.09 \\
\hline OT time & 1.03 & $1.00-1.06$ & 0.05 & 0.045 \\
\hline \multicolumn{5}{|l|}{ Surgical specialty } \\
\hline Cardiothoracic (reference level) & 1 & & & $<0.01$ \\
\hline $\begin{array}{l}\text { Ear, nose and throat; plastics; } \\
\text { maxillofacial }\end{array}$ & 3.00 & $0.67-13.42$ & 0.15 & \\
\hline Endocrine & 1 & Undefined & 1.00 & \\
\hline Gastrointestinal & 0.66 & $0.15-2.79$ & 0.57 & \\
\hline Neurological & 1.44 & $0.25-8.47$ & 0.69 & \\
\hline Obstetrics and gynaecology & 1.26 & $0.29-5.60$ & 0.76 & \\
\hline Orthopaedics & 3.18 & $0.71-14.22$ & 0.13 & \\
\hline Other & 0.07 & $0.01-0.37$ & $<0.01$ & \\
\hline Urology & 6.27 & $0.85-46.24$ & 0.07 & \\
\hline Vascular & 0.57 & $0.13-2.56$ & 0.46 & \\
\hline \multicolumn{5}{|l|}{ Hypotensive episodes } \\
\hline None (Reference level) & 1 & & & $<0.01$ \\
\hline $1-4$ & 3.20 & $1.23-8.28$ & 0.017 & \\
\hline$>5$ & 6.57 & $3.23-13.37$ & $<0.01$ & \\
\hline
\end{tabular}

Predictors associated with pressure ulcer development within 72 hours of intensive care unit admission

Univariate analysis showed only age and APACHE II score to be statistically significant, thus these predictors were subsequently included in a multivariable logistic regression model. From this model, the independent effects of both predictors were found to be nonsignificant. Model fit was good as the Hosmer-Lemeshow Goodness of Fit Test was non-significant $(\mathrm{p}=0.29)$. Furthermore, there was no evidence that additional covariates would improve the model $(p=0.20)$ by the Wald link specification test.

\section{Predictors associated with pressure ulcer} development over entire admission

On initial univariate Cox regression, surgical speciality, cumulative OT time, APACHE II score and number of hypotensive episodes in the OT were found to be significantly associated with the development of PU. These variables, as well as the potential confounders of age and gender, were included in the final multiple regression analysis. The final Cox proportional hazards regression model found that length of time in OT $(p=0.045)$, surgical speciality $(p<0.001), 1-4$ hypotensive episodes $(\mathrm{p}=0.017)$ and $>5$ hypotensive episodes $(\mathrm{p}<0.0005)$ were significantly associated with PU risk.

Each minute increase in length of time in OT increased the risk of PU development by $0.1 \%(\mathrm{p}=0.045$, hazard ratio (HR) 1.001; 95\% CI: 1.000 to 1.001). The surgical speciality 'other' conferred a $92.70 \%$ decreased risk of the event compared with cardiothoracic surgery ( $\mathrm{p}<0.01$, HR0.073; 95\%CI: 0.014 to 0.371). Experiencing 1-4 hypotensive episodes increased the risk of PU by 3.2 times compared with experiencing no hypotensive episodes during surgery ( $\mathrm{p}=0.017$, HR3.20, 95\% CI: 1.23 to 8.28 ). Finally, more than five hypotensive episodes during surgery conferred a 6.57-fold increase in PU risk when compared with no hypotensive episodes ( $\mathrm{p}<0.01$, HR 6.57, 95\% CI: 3.23 to 13.37). Our multivariate Cox regression model satisfied the P roportional $\mathrm{H}$ azards Assumption $(\mathrm{p}=0.97)$.

\section{Predictors associated with number of pressure ulcer} On initial univariate negative binomial regression, APACHE II score, OT time, surgical speciality and vasopressor administration were found to be statistically significant at the 0.10 level of significance. Consequently, these predictors were included in a multivariable negative binomial regression model. From this model, the independent effects of APACHE II score $(\mathrm{p}<0.01)$, OT time $(\mathrm{p}<0.01)$, surgical speciality $(\mathrm{p}<0.01)$ and vasopressor administration in OT $(\mathrm{p}<0.01)$ were found to be associated with PU number. An increase of one unit in APACHE II score was found to increase the incidence rate of $\mathrm{PU}$ by $19 \%(\mathrm{p}<0.01$, Incidence rate ratio (IRR): $1.19 ; 95 \% \mathrm{CI}: 1.13$ to 1.25 ), while the incidence rate was found to similarly increase by $19 \%$ for each additional hour of OT time $(\mathrm{p}<0.01$, IRR: $1.19 ; 95 \%$ CI: 1.10 to 1.28 ). Though the overall effect of surgical speciality was found to be significant $(\mathrm{p}<0.01)$, only two specialties were found to significantly differ from cardiothoracic surgery with respect to incidence rates; these being the combined speciality of ear, nose, throat, plastics and maxillofacial $(\mathrm{p}<0.01$, IRR: 0.06 ; $95 \%$ CI: 0.01 to 0.46 ) and endocrine ( $\mathrm{p}<0.01$, IRR: 0.01 ; $95 \%$ CI: 0 to 0.02 ). Both resulted in reduced incidence rates. It must be noted that estimates for vasopressor administration are not reported due to 'perfect prediction'; i.e. all patients had no PU when they did not receive any vasopressors during their index surgical case.

\section{Discussion}

Our research builds on previous studies investigating perioperative risk factors associated with PU development in a critical care setting. ${ }^{22,25,26,39-42}$

The incidence of new-onset postoperative pressure ulcer was $1.98 \%$ in our sample. This figure is comparable to published data on the Australian health care system: Webster et al. reported an incidence of $1.3 \%$ in their study of surgically acquired PUs. ${ }^{22}$

When considering perioperative variables, it is necessary to acknowledge intraoperative specific 
variables such as case length, surgical speciality, and hypotensive episodes; as well as ICU specific (i.e postoperative) variables such as ICU length of stay. In our study we attempted to analyse both types of perioperative factors.

Our findings suggest that out of our studied perioperative variables, there were no significant predictors of PU development within 72 hours of ICU admission. However, OT time, surgical speciality, and number of hypotensive episodes were significant predictors for the development of PU for the entire duration of each ICU admission. Additionally, APACHE II score, OT time and surgical speciality correlated strongly with the number of PUs that occurred per admission.

\section{Pressure ulcers within 72 hours}

of intensive care unit admission

We initially hypothesised that perioperative risk factors increase the likelihood of PU within the first 72 hours of ICU admission. However, our results did not support this hypothesis and it may be that perioperative variables do not exert their influence on PU development until after this period. Indeed, previous analyses revealed mean time to PU may be as early as five hours ${ }^{44}$ or as late as six days after admission. ${ }^{45}$ Such varied results make it challenging to characterise individual PUs as preventable events by obscuring the timeframe when certain variables impact on their formation, subsequently raising difficulties when considering focused risk management strategies.

There is a distinct lack of research into the timing of PU development and further study is necessary to delineate the exact timeframe of this effect.

\section{Pressure ulcer risk over entire} intensive care unit admission

We found case length to be significantly associated with PU development, which parallels previous studies: in a cohort of 208 surgical patients, Schoonhoven et al. ${ }^{40}$ reported that for every 30 minutes over four hours in the OT, the risk of developing a PU increased by approximately $33 \%$. Papantonio et al. ${ }^{20}$ also found that OT time was strongly associated with PU occurrence, with a mean total OR time of 374.1 minutes in PU-positive patients compared witjh a mean total OR time of 334.6 minutes in PU-negative patients. However, the results for both of these studies should be carefully interpreted due to their small sample size. Conversely, in recent research conducted on an Australian cohort, Webster et al. ${ }^{22}$ found that length of surgery was not associated with PU development. Likewise, using propensity matching, O'Brien et al. ${ }^{24}$ reported that case length was not associated with postoperative PU. Importantly, we analysed cumulative case length over a patient's entire admission, which differs from preceding studies - treating case length in this manner is a unique concept warranting further investigation.

Hypotension predisposes towards impaired peripheral
Table 8. Univariable negative binomial regression analysis-predictors for pressure ulcer number

\begin{tabular}{|c|c|c|c|c|}
\hline \multirow[t]{2}{*}{ Predictor } & \multicolumn{4}{|c|}{ Univariable analysis } \\
\hline & $\begin{array}{l}\text { Unadjusted } \\
\text { IRR }\end{array}$ & $95 \% \mathrm{Cl}$ & p-value & $\begin{array}{l}\text { Overall } \\
\text { p-value }\end{array}$ \\
\hline Age, year & 1.00 & $0.99-1.01$ & 0.99 & 0.99 \\
\hline APACHE II score & 1.19 & $1.14-1.25$ & $<0.01$ & $<0.01$ \\
\hline Vasopressor administration & \multicolumn{4}{|c|}{ not reported due to 'perfect prediction' } \\
\hline OT time & 1.18 & $1.10-1.27$ & $<0.01$ & $<0.01$ \\
\hline \multicolumn{5}{|l|}{ Surgical speciality } \\
\hline Cardiothoracic (reference level) & 1 & & & $<0.01$ \\
\hline $\begin{array}{l}\text { Ear, nose and throat; plastics; } \\
\text { maxillofacial }\end{array}$ & 0.06 & $0.01-0.30$ & $<0.01$ & \\
\hline Endocrine & 0.01 & $0-0.02$ & $<0.01$ & \\
\hline Gastrointestinal & 0.20 & $0.06-0.64$ & 0.01 & \\
\hline Neurological & 0.16 & $0.04-0.64$ & 0.01 & \\
\hline Obstetrics and gynaecology & 0.05 & $0.01-0.48$ & 0.05 & \\
\hline Orthopaedics & 0.29 & $0.08-1.02$ & 0.06 & \\
\hline Other & 0.11 & $0.01-1.05$ & 0.03 & \\
\hline Urology & 0.13 & $0.02-0.85$ & 0.01 & \\
\hline Vascular & 0.14 & $0.04-0.57$ & $<0.01$ & \\
\hline \multicolumn{5}{|l|}{ Hypotensive episodes } \\
\hline None (reference level) & 1 & & & 0.60 \\
\hline $1-4$ & 0.66 & $0.28-1.56$ & 0.34 & \\
\hline$>5$ & 1.08 & $0.48-2.43$ & 0.18 & \\
\hline
\end{tabular}

perfusion and increases the susceptibility of peripheral tissues to increased pressure. ${ }^{45}$ Accordingly, the number of hypotensive episodes during surgery emerged as a significant risk factor in our study. Patient visits with 1-4 hypotensive episodes during the index surgical case were more likely to result in PU, and those with $\geq 5$ episodes were at an even greater risk of developing a PU, suggesting a dose-response relationship. Schoonhoven et al. determined that longer episodes of continuous hypotension (defined in their study as systolic blood pressure $<60 \mathrm{mmHg}$ ) were associated with increased PU development, however the number of hypotensive episodes was not statistically significant. ${ }^{40}$ We investigated the number rather than the duration of hypotensive episodes - it is unclear which is the more relevant variable when considering threats to skin integrity, and overall this is an area requiring further investigation.

Interestingly, although vasopressor use is often considered a proxy for tissue hypoperfusion, our results indicate that inotrope administration during surgery was not a significant predictor of PU development in 
this population. Although Tschannen et al. ${ }^{23}$ demonstrated that the use of vasoactive medications to support a patient's blood pressure increased the incidence of PU development in the surgical patient by $33 \%$, our findings are consistent with research by $\mathrm{O}^{\prime}$ Brien et al., ${ }^{24}$ who concluded that intraoperative vasopressor use was not associated with postoperative PU development.

With respect to surgical speciality, the risk of PU was significantly reduced for the speciality of 'other' when compared with cardiothoracic surgery. No other specialties were found to be significant when compared with cardiothoracic surgery. Aaronovitch ${ }^{6}$ reported that surgery types most commonly associated with PU development were cardiac, thoracic and vascular surgery. Patients undergoing vascular and cardiac surgery are likely to be suffering from pre-existing vascular pathology as well as a degree of haemodynamic compromise, and cardiac procedures often necessitate extracorporeal circulation intraoperatively. These alterations in blood flow could predispose tissue to PU development. Accordingly, in a study of 125 elective surgical patients, Kemp et al. ${ }^{46}$ determined that extracorporeal circulation was associated with PU development post-operatively.

In our analysis, APACHE II score did not reach significance as a predictor of postoperative PU development, a result which previous studies corroborate. ${ }^{47,48}$ Furthermore, age was not correlated to

Table 9. Multivariable negative binomial regression analysispredictors for pressure ulcer number

\begin{tabular}{|c|c|c|c|c|}
\hline \multirow[t]{2}{*}{ Predictor } & \multicolumn{4}{|c|}{ Multivariable analysis } \\
\hline & $\begin{array}{l}\text { Adjusted } \\
\text { IRR }\end{array}$ & $95 \% \mathrm{Cl}$ & p-value & $\begin{array}{l}\text { Overall } \\
\text { p-value }\end{array}$ \\
\hline \multicolumn{5}{|l|}{ Age, year } \\
\hline APACHE II score & 1.19 & $1.13-1.25$ & $<0.01$ & $<0.01$ \\
\hline OT time & 1.19 & $1.10-1.28$ & $<0.01$ & $<0.01$ \\
\hline \multicolumn{5}{|l|}{ Surgical speciality: } \\
\hline Cardiothoracic (reference level) & 1 & & & $<0.01$ \\
\hline $\begin{array}{l}\text { Ear, nose and throat; plastics; } \\
\text { maxillofacial }\end{array}$ & 0.06 & $0.01-0.46$ & 0.01 & \\
\hline Endocrine & 0.01 & $0-0.02$ & $<0.01$ & \\
\hline Gastrointestinal & 0.21 & $0.04-0.99$ & 0.05 & \\
\hline Neurological & 0.26 & $0.05-1.31$ & 0.10 & \\
\hline Obstetrics and gynaecology & 0.11 & $0.01-0.95$ & 0.05 & \\
\hline Orthopaedics & 0.56 & $0.11-2.90$ & 0.49 & \\
\hline Other & 0.73 & $0.04-13.12$ & 0.83 & \\
\hline Urology & 0.16 & $0.02-1.25$ & 0.08 & \\
\hline Vascular & 0.28 & $0.04-1.90$ & 0.19 & \\
\hline
\end{tabular}

PU development in our study. This has also been reflected i $\mathrm{n}$ o ther i nvestigations; a fter $\mathrm{m}$ ultivariate analysis, Tschannen et al. ${ }^{23}$ concluded that age was not a significant predictor for the development of PU in their cohort of critically ill patients, a finding which is further supported by Theaker et al. ${ }^{27}$

\section{Predictors of pressure ulcer number}

Previously, few studies have examined the relationship between perioperative variables and the number of PUs that occur per patient or patient admission. We found increasing APACHE II score was significantly associated with increasing numbers of postoperative PUs. The APACHE II score ${ }^{37}$ is used to estimate ICU mortality and is considered a surrogate marker for disease severity. As this score amalgamates numerous variables, we postulate the existence of common pathophysiological processes between higher APACHE II scores and PU development. Pertinent variables used to calculate this score include history of severe organ failure, acute renal failure, mean arterial pressure, Glasgow Coma Scale (GCS), haematocrit and electrolyte levels. Delmore et al. demonstrated respiratory failure, liver failure and septic shock were independent predictors of acute skin failure in ICU patients, ${ }^{49}$ although notably their study was not restricted to postoperative patients. Lewicki et al. ${ }^{5}$ identified $l$ ower $p$ reoperative $h$ aematocrit a nd haemoglobin as significant for PU development in their postoperative patient sample, and these results are mirrored by Papantonio et al. ${ }^{20}$

Immobility is recognised as an important factor in PU development-previous studies have identified nonambulatory status as a predictor for PU occurrence, ${ }^{42}$ and those who are more obtunded, as represented by lower GCS, may therefore be at increased risk.

Increasing OT time was similarly correlated with PU number. This may relate to longer periods of time over which pressure is exerted on a patient's skin, predisposing them to develop more than one PU. ${ }^{50}$

Surgical speciality was also associated with PU number: endocrine surgery and the combined specialties of ear, nose, throat, plastics and maxillofacial surgery both decreased the incidence rates of PU in our sample. Interestingly, these variables are distinct from those that influence the overall risk of PU occurrence during ICU admission. Similarly, though the number of hypotensive episodes during surgery was associated with overall risk for PU development, this variable did not affect the number of PUs that developed per admission. There may be distinct pathophysiological processes underlying the overall risk of PU occurrence compared with the development of multiple PUs, and this area would benefit from closer scrutiny.

\section{Limitations}

Our study has several limitations. Data on vasopressor administration were missing in a large proportion of our sample. Additionally, a number of patients were missing data on time spent in the OT. Surgeries subsequent to the 
Table 10. Univariable logistic regression analysis-predictors for pressure ulcer occurrence $<72$ hours of intensive care unit admission

\begin{tabular}{|c|c|c|c|c|}
\hline \multirow[t]{2}{*}{ Predictor } & \multicolumn{4}{|c|}{ Univariable analysis } \\
\hline & $\begin{array}{l}\text { Adjusted } \\
\text { OR }\end{array}$ & $95 \% \mathrm{Cl}$ & p-value & $\begin{array}{l}\text { Overall } \\
\text { p-value }\end{array}$ \\
\hline Age, year & 0.97 & $0.94-1.00$ & 0.08 & 0.08 \\
\hline APACHE II score & 0.93 & $0.86-1.01$ & 0.09 & 0.09 \\
\hline Vasopressor administration & 1.00 & Undefined & 1.00 & 1.00 \\
\hline OT time & 1.03 & $0.95-1.11$ & 0.50 & 0.50 \\
\hline \multicolumn{5}{|l|}{ Surgical-speciality } \\
\hline Cardiothoracic (reference level) & 1 & & & 0.55 \\
\hline $\begin{array}{l}\text { Ear, nose and throat; plastics; } \\
\text { maxillofacial }\end{array}$ & 15.00 & $0.43-524.52$ & 0.14 & \\
\hline Endocrine & \multicolumn{4}{|c|}{ No observations } \\
\hline Gastrointestinal & 2.83 & $0.13-61.23$ & 0.51 & \\
\hline Neurological & 9.00 & $0.40-203.30$ & 0.17 & \\
\hline Obstetrics and gynaecology & 3.00 & $0.04-228.66$ & 0.62 & \\
\hline Orthopaedics & 10.20 & $0.47-222.45$ & 0.14 & \\
\hline Other & 3.00 & $0.04-228.66$ & 0.62 & \\
\hline Urology & 9.00 & $0.22-362.48$ & 0.24 & \\
\hline Vascular & 4.85 & $0.20-118.61$ & 0.33 & \\
\hline \multicolumn{5}{|l|}{ Hypotensive episodes } \\
\hline None (reference level) & 1 & & & 0.26 \\
\hline $1-4$ & 0.52 & $0.09-2.88$ & 0.45 & \\
\hline$>5$ & 2.37 & $0.65-8.67$ & 0.19 & \\
\hline
\end{tabular}

Table 11. Multivariable logistic regression analysis-predictors for pressure ulcer occurrence $<72$ hours of intensive care unit admission

\begin{tabular}{|c|c|c|c|c|}
\hline \multirow[t]{2}{*}{ Predictor } & \multicolumn{4}{|c|}{ Multivariable analysis } \\
\hline & $\begin{array}{l}\text { Adjusted } \\
\text { OR }\end{array}$ & $95 \% \mathrm{Cl}$ & p-value & $\begin{array}{l}\text { Overall } \\
\text { p-value }\end{array}$ \\
\hline Age & 0.98 & $0.95-1.01$ & 0.25 & 0.25 \\
\hline APACHE II score & 0.96 & $0.56-27.81$ & 0.17 & 0.17 \\
\hline
\end{tabular}

index case were not analysed for other perioperative variables, however it remains plausible that these procedures further influenced PU development. Moreover, although APACHE II score was included in our analysis we did not individually examine potentially significant patient variables before the index surgical case, such as comorbid diseases, mobility and nutritional status. Our study demonstrated a wide range of manifestations of pressure damage, which may be a further limitation. Most PUs included in our analyses were superficial (i.e. category I or II), although there also existed a pool of more severe wounds and a group of mucosal PUs. This heterogeneity of clinical presentations may have hindered identification of specific risk factors for specific types of PU.

Our study attempted to examine the effect of both intra- and postoperative (i.e. ICU) variables on PU occurrence. However, delineating these factors and their individual influence on PU formation is difficult to achieve in a retrospective study.

Our study only recorded PU that developed within the ICU and patients were not followed up subsequent to discharge from the ICU, which precluded the identification of any PU occurring later in their hospital admission. Though critically ill patients are a population at an inherently increased risk of developing PUs, it is unclear if particular variables continue to pose a risk to skin injury after discharge. Finally, any generalisations from our research are limited to a similar subset of postsurgical ICU patients.

\section{Conclusion}

There exist a multitude of perioperative variables that may impact PU development in critically ill postoperative patients. Our study suggests that surgical speciality, length of time in OT, and number of hypotensive episodes in OT are associated with PU development during post-surgical ICU admission, whereas no specific variables a re associated with P U development within the first 72 hours of ICU admission.

APACHE II score, OT time and surgical speciality were significantly correlated with the number of PUs developed during admission. These results are clinically pertinent: the perioperative period presents a number of risks to skin integrity, and these may exert their effect well into the ICU admission period. It is imperative to identify and mitigate these factors in order to reduce PU incidence, morbidity and mortality. Jwc

\section{Acknowledgements}

The authors would like to thank Anna Dubrovsky (BSc Hons, MPH), Project Manager at Queensland University of Technology's School of Nursing, for assistance with data collection and consolidation.

\section{References}

1 National Pressure Ulcer Advisory Panel. 2016. NPUAP Pressure Injury Stages. https://tinyurl.com/gnvnhvg (accessed 18 July 2018)

2 Graves N, Birrell F, Whitby M. Effect of pressure ulcers on length of hospital stay. Infect Control Hosp Epidemiol 2005; 26(3):293-297

3 Reddy M, Gill SS, Rochon PA. Preventing pressure ulcers: a systematic review. JAMA 2006; 296(8):974-984. https://doi.org/10.1001/ jama.296.8.974

4 Elliott R, McKinley S, Fox V. Quality improvement program to reduce the prevalence of pressure ulcers in an intensive care unit. Am J Crit Care 2008; 17(4):328-334

5 Lewicki LJ, Mion L, Splane KG et al. Patient risk factors for pressure ulcers during cardiac surgery. AORN J 1997; 65(5):933-942. https://doi. org/10.1016/S0001-2092(06)62976-1

6 Aronovitch SA. Intraoperatively acquired pressure ulcer prevalence: a national study. J Wound Ostomy Continence Nurs 1999; 26(3):130-136

7 Aronovitch SA. Intraoperatively acquired pressure ulcers: are there common risk factors? Ostomy Wound Manage 2007; 53(2):57-69

8 Miles S, Fullbrook P, Nowicki T, Franks C. Decreasing pressure injury prevalence in an Australian general hospital: A 10-year review. Wound Practice Research 2013; 21(4):148-156

9 House S, Giles T, Whitcomb J. Benchmarking to the international pressure ulcer prevalence survey. J Wound Ostomy Continence Nurs 
2011; 38(3):254-259. https://doi.org/10.1097/WON.0b013e318215fa48 10 Jenkins ML, O'Neal E. Pressure ulcer prevalence and incidence in acute care. Adv Skin Wound Care 2010; 23(12):556-559. https://doi. org/10.1097/01.ASW.0000391184.43845.c1

11 Vanderwee K, Defloor T, Beeckman D et al. Assessing the adequacy of pressure ulcer prevention in hospitals: a nationwide prevalence survey. BMJ Qual Saf 2011; 20(3): 260-267. https://doi.org/10.1136/ bmjqs.2010.043125

12 Gardiner J, Reed P, Bonner J et al. Incidence of hospital-acquired pressure ulcers - a population-based cohort study. Int Wound J 2016; 13(5):809-820. https://doi.org/10.1111/iwj.12386

13 de Laat EH, Schoonhoven L, Pickkers $P$ et al. Epidemiology, risk and prevention of pressure ulcers in critically ill patients: a literature review. J Wound Care 2006; 15(6):269-275. https://doi.org/10.12968/ jowc.2006.15.6.26920

14 NSW Clinical Excellence Comission. 2015 NSW Pressure Injury Point Prevalence Survey Report. Clinical Excellence Commission Pressure Injury Prevention Project Monitoring and Auditing Framework 2016. 15 Victorian Quality Council. (2006) Statewide PUPPS report - pressure ulcer point prevalence survey 3. https://tinyurl.com/y9upy6ko. [AQ19: please check link] (accessed July 2018).

16 Demarré L, Van Lancker A, Van Hecke A et al. The cost of prevention and treatment of pressure ulcers: a systematic review. Int J Nurs Stud 2015; 52(11):1754-1774. https://doi.org/10.1016/j.ijnurstu.2015.06.006

17 Clough NP. The cost of pressure area management in an intensive care unit. J Wound Care 1994; 3(1):33-35. https://doi.org/10.12968/ jowc.1994.3.1.33

18 Queensland Health. 2009. Patient safety and quality plan 2008-2012. https://tinyurl.com/y9yt72cn (accessed 18 July 2018)

19 Nguyen $\mathrm{KH}$, Chaboyer W, Whitty JA. Pressure injury in Australian public hospitals: a cost-of-illness study. Aust Health Rev 2015; 39(3):329-336. https://doi.org/10.1071/AH14088

20 Papantonio CT, Wallop JM, Kolodner KB. Sacral ulcers following cardiac surgery: incidence and risks. Adv Wound Care 1994; 7(2):24-36

21 Schultz A, Bien M, Dumond K et al. Etiology and incidence of pressure ulcers in surgical patients. AORN J 1999; 70(3):434, 437-440, 443-439 22 Webster J, Lister C, Corry J et al. Incidence and risk factors for surgically acquired pressure ulcers: a prospective cohort study

investigators. J Wound Ostomy Continence Nurs 2015; 42(2):138-144. https://doi.org/10.1097/WON.0000000000000092

23 Tschannen D, Bates O, Talsma A, Guo Y. Patient-specific and surgical characteristics in the development of pressure ulcers. Am J Crit Care 2012; 21(2):116-125. https://doi.org/10.4037/ajcc2012716

24 O'Brien DD, Shanks AM, Talsma A et al. Intraoperative risk factors associated with postoperative pressure ulcers in critically ill patients: a retrospective observational study. Crit Care Med 2014; 42(1):40-47. https://doi.org/10.1097/CCM.0b013e318298a849

25 Cox J. Pressure ulcer development and vasopressor agents in adult critical care patients: a literature review. Ostomy Wound Manage 2013; 59(4):50-54

26 Cox J. Predictors of pressure ulcers in adult critical care patients. Am J Crit Care 2011; 20(5):364-375. https://doi.org/10.4037/ajcc2011934

27 Theaker C, Mannan M, Ives N, Soni N. Risk factors for pressure sores in the critically ill. Anaesthesia 2000; 55(3):221-224. https://doi. org/10.1046/j.1365-2044.2000.01216.x

28 Jiricka MK, Ryan P, Carvalho MA, Bukvich J. Pressure ulcer risk factors in an ICU population. Am J Crit Care 1995; 4(5):361-367

29 Antle D, Leafgreen P. Reducing the incidence of pressure ulcer development in the ICU. Am J Nurs 2001; 101(5):24EE-24JJ

30 Bours G, Laat E, Halfens R, Lubbers M. Prevalence, risk factors and prevention of pressure ulcers in Dutch intensive care units. Intensive Care Med 2001; 27(10):1599-1605. https://doi.org/10.1007/s001340101061

31 Boyle M, Green M. Pressure sores in intensive care: defining their incidence and associated factors and assessing the utility of two pressure sore risk assessment tools. Aust Crit Care 2001; 14(1):24-30. https://doi.
org/10.1016/S1036-7314(01)80019-9

32 Keller P, Wille J, van Ramshorst B, van der Werken C. Pressure ulcers in intensive care patients: a review of risks and prevention. Intensive Care Med 2002; 28(10):1379-1388. https://doi.org/10.1007/s00134-002-1487-z 33 Gefen A. How much time does it take to get a pressure ulcer? Integrated evidence from human, animal, and in vitro studies. Ostomy Wound Manage 2008; 54(10):26-28, 30-35

34 Le KM, Madsen BL, Barth PW et al. An in-depth look at pressure sores using monolithic silicon pressure sensors. Plast Reconstr Surg 1984; 74(6):745-754. https://doi.org/10.1097/00006534-198412000-00001

35 Scott SM, Mayhew PA, Harris EA. Pressure ulcer development in the operating room. Nursing implications. AORN J 1992; 56(2):242-250. https://doi.org/10.1016/S0001-2092(07)68683-9

36 Stordeur S, Laurent S, D'Hoore W. The importance of repeated risk assessment for pressure sores in cardiovascular surgery. J Cardiovasc Surg (Torino) 1998; 39(3):343-349

37 Knaus WA, Draper EA, Wagner DP, Zimmerman JE. APACHE II: a severity of disease classification system. Crit Care Med 1985; 13(10):818829. https://doi.org/10.1097/00003246-198510000-00009

38 Baharestani MM, Black JM, Carville $\mathrm{K}$ et al. Dilemmas in measuring and using pressure ulcer prevalence and incidence: an international consensus. Int Wound J 2009; 6(2):97-104. https://doi. org/10.1111/j.1742-481X.2009.00593.x

39 Lewicki LJ, Mion L, Splane KG et al. Patient risk factors for pressure ulcers during cardiac surgery. AORN J 1997; 65(5):933-942. https://doi. org/10.1016/S0001-2092(06)62976-1

40 Schoonhoven L, Defloor T, van der Tweel I et al. Risk indicators for pressure ulcers during surgery. Appl Nurs Res 2002; 15(3):163-173. https://doi.org/10.1053/apnr.2002.34145

41 Slowikowski GC, Funk M. Factors associated with pressure ulcers in patients in a surgical intensive care unit. J Wound Ostomy Continence Nurs 2010; 37(6):619-626. https://doi.org/10.1097/ WON.0b013e3181f90a34

42 Eachempati SR, Hydo LJ, Barie PS. Factors influencing the

development of decubitus ulcers in critically ill surgical patients. Crit Care Med 2001; 29(9):1678-1682. https://doi. org/10.1097/00003246-200109000-00004

$\mathbf{4 3} \mathrm{Kim} \mathrm{HJ}$, Jeong IS. [Optimal time interval for position change for ICU patients using foam mattress against pressure ulcer risk]. J Korean Acad Nurs 2012; 42(5):730-737. https://doi.org/10.4040/jkan.2012.42.5.730

44 Baumgarten M, Margolis DJ, Localio AR et al. Pressure ulcers among elderly patients early in the hospital stay. J Gerontol A Biol Sci Med Sci 2006; 61(7):749-754

45 Man SP, Aung-Yeung TW. Hypotension Is a Risk Factor for New Pressure Ulcer Occurrence in Older Patients After Admission to an Acute Hospital. J Am Med Dir Assoc 2013; 14(8):627.https://doi.org/10.1016/j. jamda.2013.05.003

46 Kemp MG, Keithley JK, Smith DW, Morreale B. Factors that contribute to pressure sores in surgical patients. Res Nurs Health 1990; 13(5):293301. https://doi.org/10.1002/nur.4770130505

47 Frankel H, Sperry J, Kaplan L. Risk factors for pressure ulcer

development in a best practice surgical intensive care unit. Am Surg 2007; 73(12):1215-1217

48 Theaker C, Kuper M, Soni N. Pressure ulcer prevention in intensive care? a randomised control trial of two pressure-relieving devices. Anaesthesia 2005; 60(4):395-399. https://doi. org/10.1111/j.1365-2044.2004.04085.x

49 Delmore B, Cox J, Rolnitzky L et al. Differentiating a pressure ulcer from acute skin failure in the adult critical care patient. Adv Skin Wound Care 2015; 28(11):514-524. https://doi.org/10.1097/01. ASW.0000471876.11836.dc

$\mathbf{5 0}$ Nathalie S. Epidemiology and pathophysiology of pressure ulcers. Eur Geriatr Med 2012; 3:S19-S20. https://doi.org/10.1016/j. eurger.2012.07.415

\section{JWC available at $w w w . m$ a $g \circ n \mid i n$ l i b r a r y.c o m}

Register for free and take advantage of these great benefits and features:

- Save JWC articles for quick access

- Save your searches: great if you frequently search for the same criteria

- Get citation alerts to track citations to specific articles

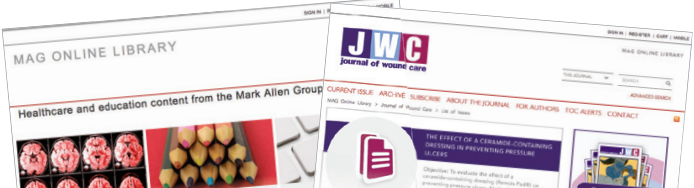

